\title{
Assessment of Potential for Biodiesel Feedstock of Selected Wild Plant Oils Indigenous to Botswana
}

\author{
Jerekias Gandure (Corresponding author) \\ Mechanical Engineering Department, University of Botswana \\ Private bag 0061, Gaborone, Botswana \\ Tel: 267-7268-3654Ｅ-mail: gandurej@mopipi.ub.bw
}

Clever Ketlogetswe

Mechanical Engineering Department, University of Botswana

Private bag 0061, Gaborone, Botswana

Tel: 267-7147-3419Ｅ-mail: ketloget@mopipi.ub.bw

$\begin{aligned} & \text { Received: October 11, } 2011 \quad \text { Accepted: October 31, } 2011 \quad \text { Published: December 31, } 2011 \\ & \text { doi:10.5539/eer.v1n1p61 }\end{aligned}$ URL: http://dx.doi.org/10.5539/eer.v1n1p61

\begin{abstract}
Biodiesel is attracting increasing attention worldwide as a blending component or a direct replacement of petroleum diesel fuel in transport sector.The challenge to scientists and engineers is to identify appropriate feedstocks for biodiesel production. The majority of potential feedstocks are edible species which are at the centre of the "fuel versus food" debate. It is therefore imperative for scientists and engineers to continue the search for biodiesel feedstocks that do not compete with food security. This work investigated some properties of selected wild plant oils to assess suitability as feedstock for biodiesel production. Properties reviewed include oil yield levels, oil acidity, percentage of free fatty acids and the level of energy content. The wild plant oils under review were extracted from Scelerocarya birrea, Tylosema esculentum and Ximenia caffra fruit seeds. In addition, Jatropha oil was analysed for purposes of comparison. Thermal properties of wild plant oils were compared with those of petroleum diesel. Results indicate that wild plant oils investigated had sufficiently high oil yield levels desirable for potential feedstocks for biodiesel production. The energy content levels of wild plant oils were marginally lower than that of petroleum diesel with a maximum variation of $5.7 \mathrm{MJ} / \mathrm{Kg}$.
\end{abstract}

Keywords: Biodiesel, Feedstock, Indigenous, Properties

\section{Introduction}

The desire to establish energy security and to develop alternatives to finite fossil fuel resources has stimulated research in the use of renewable agriculture based materials as feedstocks. The majority of efforts to date have focused on biodiesel which has been shown to give engine performance that is generally comparable to that of conventional diesel fuel while reducing engine emissions of particulates, hydrocarbons and carbon monoxide (Graboski, 1998; Shu-Mei et al., 2009). Biodiesel is attracting increasing attention worldwide as a blending component or a direct replacement of petrodiesel fuel in vehicle engines (Demirbas et al., 2006; Tsoutsos et al., 2009). Biodiesel can be produced from any material that contains fatty acids, bonded to other molecules or present as free fatty acids. As such, various vegetable oils can be used as feedstocks for biodiesel production, the choice of which largely depends on variables such as local availability, transportation and processing costs, government support and performance as a fuel (Haas et al., 2006). Given the limited availability of such sources, and to avoid the "food versus fuel" conflict, the non-edible jatropha plant, whose fruit is oil-rich, is receiving widespread attention world over. Jatropha has been identified as a major potential source for sustainable biodiesel production due to its high oil content ranging between approximately $30-40 \%$ by weight, good oil characteristics and promising sustainability profile (Young, 2011). It is widely planted in the tropics and has strong potential for cultivation in marginal semi-arid or waste lands, hence not competing directly with food crops (Heller, 1996; Dukek, 2011). 
The fuel properties of biodiesel depend on the feedstock, precisely on the nature and relative quantity of the alkyl groups attached to the glycerine molecule (Razon, 2009). Knothe (2005) and Moser (2009) investigated the dependence of fuel properties on the characteristic fatty acid profile given by different feedstocks. They found out that while the detailed structure of each fatty acid has an impact on the fuel properties, the most frequently cited parameters are the average chain length and the degree of unsaturation of the fatty acids. Based on the behaviour of fatty acid methyl esters, they generally concluded that the cetane number, heat of combustion, melting point, viscosity and the oxidative stability increase as the chain length increases and decrease as the number of double bonds increase. Aguirrezabal et al. (2009) also investigated the influence of fatty acid compositions on the quality of biodiesel. The authors simulated variability in sunflower oil quality for biodiesel production and report that biodiesel produced using sunflower oils have different qualities which are influenced by factors such as weather conditions and agricultural practices. They further report that fatty acid composition varies according to geographical location, altitude where the plant is grown and other environmental factors. Data on how various fatty acid compositions of different sources of oil can influence biodiesel quality is important. This could exclude some vegetable oils from being used as feedstock for biodiesel production and in any case, the feedstock quality also influences the type of processing to be undertaken (Moser, 2009). Similarly, Van Gerpen et al. (2004) recommend a free fatty acid (FFA) value of less than 5\%.

Methods of reducing FFA in the feedstock include neutralisation with an alkaline solution prior to transesterification and two-stage processing; namely, acid esterification followed by alkaline transesterification (Gemma et al, 2004). Calorific value or heat of combustion is another fuel property that indicates the suitability of fatty compounds as biodiesel feedstock or fuel. Heats of combustion of fatty esters and triglycerides are in the approximate range of $1300-3500 \mathrm{kcal} / \mathrm{mole}$ for fatty acid esters with C8 - C22 (Knothe et al., 2005).

There may be a fatty compound that provides optimal fuel properties while minimizing negative environmental effects. According to Knothe (2005), a mixture consisting of methyl oleates, and a mixture of shorter chain esters derived from palmitic and oleic acids, and esters derived from decanoic acid appears to be an ideal mixture for biodiesel feedstock.The challenge is to identify a fatty compound that will meet all the requirements for an alternative transport fuel. However, no feedstock seems to exist that fulfils all the requirements. Considering the extremely huge diversity of plants in the world, it is quite likely that plants that will play importantroles either as bulk or additive ingredients will be found. The search for new alternative feedstock plant oils for biodiesel production has stimulated further investigation on indigenous plant oils. The current study seeks to establish some properties of virgin plant oils indigenous to Botswana as potential feedstock for biodiesel production.

The plant species under review are Sclerocarya birrea (Marula), Tylosema esculentum (Morama), Ximenia caffra (Morethologa) and Jatropha. Jatropha, though not native to Botswana, was considered for purposes of benchmarking since it is largely regarded to be a suitable feedstock for production of biodiesel.Marula tree is indigenous to most parts of Southern Africa. It is widely distributed all over Botswana, but is concentrated in the north eastern part of the country. The tree grows in warm and dry climatic conditions, and produces oval fruits that turn pale yellow when ripe. Each fruit has a hard wood seed that contains mostly two oil rich nuts. Tylosema esculentum, also known as the desert bean, is a leguminous plant that grows in the sand of the Kalahari Desert. The plant spreads over the surface of the ground and produces heavily under the warm and dry climatic conditions of the desert. Ximenia caffra is a shrub that sometimes grows into a big tree. It mostly grows in mountainous areas, thrives under dry climatic conditions, and produces oval fruits that turn red when ripe. Each fruit has one seed that is rich in oil. The fact that these wild plants grow in drier climatic conditions where common oil seeds such as soy bean cannot thrive has stimulated interest in their oil as a potential feedstock for Botswana's future biodiesel industry.

\section{Materials and Methods}

\subsection{Oil extraction}

Chemical extraction method was used to establish actual oil yield levels of the selected wild fruit nuts. The process had five stages namely seed grinding, solvent extraction, filtration, distillation and purging. For each selected species $200 \mathrm{~g}$ of nuts were ground into powder using a mini grinding machine. The mini grinder was charged with $50 \mathrm{~g}$ of selected nuts at a time and run for approximately 30 seconds. The operation was repeated to increase the degree of fineness of the powder. The powder was then used in the solvent extraction process. The solvent was prepared by mixing approximately $300 \mathrm{ml}$ of hexane and $100 \mathrm{ml}$ of iso-propyl alcohol in a $500 \mathrm{ml}$ flask. The mixture ensures total extraction of all lipids as hexane extracts all non-polar lipids and iso-propyl alcohol polar lipids. Then $3 \mathrm{~g}$ of anti-bumping stones (boiling stones) were added to the mixture to ensure non-violent boiling of the solvent during oil extraction. In addition $75 \mathrm{~g}$ of powdered sample was charged into a 
thimble and placed inside a soxhlet. A soxhlet cover, condenser and heating mantle were then mounted to complete the soxhlet solvent extraction set up. The solvent was heated to boiling temperature and maintained in that phase for the entire extraction process (6 hours). After 5 syphones, the extracted liquid became clear, indicating that there was no more oil in the sample. The process was stopped and solvent/oil mixture was allowed to cool to a room temperature. Filtration process was then performed to eliminate any possibility of solid particles in the oil rich solvent. The separation of solvent from the oil was achieved through distillation process which was performed under vacuum pressure using a Rotavapor (rotary evaporator). The heating bath of the rotavapor used distilled water maintained at approximately $40^{\circ} \mathrm{C}$. The condenser used water that is slightly above freezing temperature and was maintained at that temperature using ice blocks. This process should ideally extract all the solvent, starting with hexane and then iso-propyl alcohol (due to the double bond). However, to ensure that no trace of solvent remains in the oil sample, the oil was purged with nitrogen gas (nitrogen drying) for approximately 40 minutes. Nitrogen is used because it is inert and does not react with oil components. The procedure was repeated for Ximenia caffra, Tylosema esculentum and Jatropha.

\subsection{Acid value}

Acid value measurements of oil sample extracts were carried out by titration according to ASTM method D664 (MacFarlane, 2011). Based on the same standard $125 \mathrm{ml}$ of solvent, consisting of 50\% isopropyl alcohol and 50\% toluene was prepared in a $600 \mathrm{ml}$ beaker. $5 \mathrm{~g}$ of sample was then added to the beaker, followed by $2 \mathrm{ml}$ of phenolphthalein indicator. The solutions were titrated with $0.1 \mathrm{M} \mathrm{KOH}$ to the first permanent pink colour. Three titrations were carried out for each of the four sample extracts and the average titration values determined. The acid values were determined using equation 1 and percentage of free fatty acids using equation 2 .

$$
\text { Acid Value, } A V=[(56.1 \times N) / W] \times \text { Average Titration Value }
$$

Where, $56.1=$ molecular weight of $\mathrm{KOH}$

$\mathrm{N}=$ molarity of the base

$\mathrm{W}=$ weight of sample (plant oil) in grams

$$
\text { Free Fatty Acids }(\%)=0.5 \times A V
$$

\subsection{Energy content}

The calorific values of crude plant oils and petroleum diesel (for comparison purposes) samples were determined using the IKA C200 Calorimeter system whose main components include the basic device, decomposition vessel, ignition adapter, combustion crucible and oxygen filling point. The system has automatic data acquisition through the CalWin calorimeter software which handles calculations for the calorific values of samples.

\subsubsection{Calorimeter conditions}

To determine the heating values of selected plant oil samples, $3 \mathrm{ml}$ of sample extract were weighed and placed in a weighed combustion crucible at a temperature of approximately $22^{\circ} \mathrm{C}$. The crucible was then closed up inside a decomposition vessel, which in turn was filled with oxygen at a pressure of 30 bars for 30 seconds to ensure adequate oxygen for combustion processes. The cooling water in the tank fillers was kept at initial temperature of within $18^{\circ} \mathrm{C}-24^{\circ} \mathrm{C}$ range. The oxygen-filled decomposition vessel was inserted into the measuring cell that is equipped with a magnetic stirrer. The cell cover was then closed for the test to commence. Total run time for each experiment was 8.2 minutes. The crucibles were weighed again at the end of the combustion processes to establish the amount of soot produced by the fuels during the combustion stage.

\section{Results and Discussions}

Several tests were conducted in a systematic study for analysis of calorific values, oil yield and acidity levels for selected indigenous plants oil. In addition jatropha oil extracted from species which grow natural under the Botswana's climatic conditions was also analysed. The primary objective for including jatropha in the present investigation is to create a comparative analysis between jatropha oil and the selected indigenous plant oil species found in Botswana. The experimental data were recorded as described earlier leading to the results presented in Figures 1 and 2.

The data in Figure 1 shows that jatropha has recorded relatively high oil yield when compared to the three selected indigenous plant oils. This is consistent with the observations made by several authors including Young (2011) that jatropha is now receiving widespread attention as feedstock for biodiesel production world over due to high oil yield level. However, the same data shows that Ximenia and Birrea (indigenous species) recorded relatively high oil yield with ximenia recording $64.4 \%$ by mass, thus approximately $20.3 \%$ less than the Jatropha 
local species. Comparing oil yield levels among the three selected indigenous plant oils, namely birrea, tylosema and ximenia, the results indicate that tylosema has relatively low yield level of $39.5 \%$ by mass.

Considering the energy content of the species under review, it is interesting to note that the data in the same figure shows that jatropha recorded relatively low energy content while birrea which came third in terms of the oil yield levels recorded relatively high energy content. In fact, birrea recorded $48.4 \mathrm{MJ} / \mathrm{kg}$, thus $4.2 \%$ below petrodiesel fuel, while jatropha recorded $26.8 \%$ below petrodiesel fuel. Overall, the results in Figure 1 show that energy content recorded for indigenous species compares favourably well with a maximum variation of approximately $11.5 \%$. Based on the above observations, and particularly on the energy content of some selected indigenous plant oils species found in Botswana, it is perhaps appropriate to observe that the country has natural resources to be used to stimulate the development of biodiesel industry in Botswana. The authors believe that processing of plant oils under review is likely to improve the energy content closer to the energy value recorded for petrodiesel fuel.

To further investigate the suitability of indigenous plant oils under review and jatropha oil, the authors looked into the acidity levels as demonstrated by Figure 2 .

The results in Figure 2 indicate that the level of acidity in jatropha oil and birrea indigenous plant oil are significantly above the $0.8 \mathrm{mgKOH} / \mathrm{g}$ limit specified in American standards for biodiesel (ASTM D 664). These acidity levels above $0.8 \mathrm{mgKOH} / \mathrm{g}$ suggests that such oil should not be used directly in internal combustion engines because of corrosion effects. However, the results in the same figure depict relatively low acid levels for tylosema and ximania indigenous plant oil, suggesting that such plant oils could be used directly in internal combustion engine. The authors contend that the trend demonstrated by the indigenous plant oils offers huge potential for rapid development of biodiesel industry in Botswana and further stimulate the establishment and expansion of small community business, cottage industry and the like.

\section{Conclusions and Recommendations}

This paper has examined the oil yield levels, energy content and acidity levels of plant oils for selected indigenous species in Botswana namely, birrea, Tylosema and Ximania. In addition Jatropha plant oil which grows under Botswana's climatic conditions was also examined for the same properties. The study revealed that indigenous plant oils under review recorded relatively high energy content compared with jatropha plant oil which recorded an average minimum of $36.9 \mathrm{MJ} / \mathrm{kg}$ despite its widespread attention from the energy sector world-over. The energy content levels recorded for indigenous plant oils under review range from 44.6 to 48.3 $\mathrm{MJ} / \mathrm{kg}$, with birrea recording relatively high value. This range compares favourably well with the average value of $50.3 \mathrm{MJ} / \mathrm{kg}$ for petrodiesel despite the fact that plant oils analysed were not converted into biodiesel.

The following measures are therefore proposed as likely to go a long way in stimulating the use of indigenous plant oils as feedstocks for biodiesel production in Botswana.

a) The Department of Energy and Research Institutions should create a collaborative research cluster in order to provide information on potential indigenous feedstocks for biodiesel production.

b) Authorities should come up with specific biodiesel policy frame work aimed at stimulating potential investors on biodiesel technology in Botswana.

\section{Acknowledgements}

We acknowledge support of the University of Botswana, and the Ministry of Wildlife, Tourism and Environment who granted a research permit for this work.

\section{References}

Aguirrezabal, L. A. N., Quiroz, F., Nolasco, S. M., Covi M., Izquierdo, N. G., \& Pereyra-Irujo, G. A. (2009). Variability in sunflower oil quality for biodiesel production: A Simulation study. Biomass and Bioenergy, 33, 459-468. http://dx.doi.org/10.1016/j.biombioe.2008.07.007

Demirbas, A. F. \& Balat, M. (2006). Recent advances on the production and utilization trends of bio-fuels: A global perspective. Energy Conversion and Management, 47, 2371-2381. http://dx.doi.org/10.1016/j.enconman.2 005.11 .014

Dukek, W. G. (2011). Jet Fuels. Kirk-Othmer Encyclopedia of Chemical Technology.

Gemma, V., Mercedes, M, \& Jose, A. (2004). Integrated Biodiesel Production: A comparison of different homogeneous catalysts systems. Bioresource Technology, 92, 297-305. http://dx.doi.org/10.1016/j.biortech.2003. 08.014 
Graboski, M. S. \& McCormick, R. L. (1998). Combustion of fat and vegetable oil derived fuels in diesel engines. Prog. Energy Combust. Sci, 24, 125-164. http://dx.doi.org/10.1016/S0360-1285(97)00034-8

Haas, M. J., McAloon, A. J., Yee, W. C., \& Foglia, T. A. (2006). A process model to estimate biodiesel production costs. Bioresource Technology, 97, 671-678. http://dx.doi.org/10.1016/j.biortech.2005.03.039.

Heller, J. (1996). Physic nut Jatrophacurcas: Promoting the conservation and use of underutilized and neglected crops. Institute of Plant Genetics and Crop Plant Research, Gatersleben/ International Plant Genetic Resources Institute, Rome.

Knothe, G. (2005). Dependence of biodiesel fuel properties on the structure of fatty acid alkyl esters. Fuel Process Technology, 86, 1059-1070. http://dx.doi.org/10.1016/j.fuproc.2004.11.002

Knothe, G., Steidley, K. R. (2005). Kinematic viscosity of biodiesel fuel components and related compounds. Influence of compound structure and comparison to petrodiesel fuel components. Fuel, 84, 1059-1065. http://dx.doi.org/10.1016/j.fuel.2005.01.016

MacFarlane, J. D. (2011). Determining Total Acid in Biodiesel. JM Science Inc. [Online] Available: http:// www. LaboratoryEquipment.com (May 11, 2011).

Moser, B. R. (2009). Biodiesel Production, Properties and Feedstock. In Vitro Cell Division Biology-Plant, 45, 229-266.

Razon, L. (2009). Alternative crops for biodiesel feedstock: Perspectives in Agriculture. Veterinary Science, Nutrition and Natural Resources, 4(056), 1-15.

Shu-Mei, C., Yuh-Jeen, H., Shunn-Cheng, C., \& Hsi-Hsien, Y. (2009). Effects of Biodiesel Blending on Particulate and Polycyclic Aromatic Hydrocarbon Emissions in Nano/Ultrafine/Fine/Coarse Ranges from Diesel Engine. Aerosol and Air Quality Research, 9(1), 18-31.

Tsoutsos T, Kouloumpis V, Zafiris T, Foteinis S. (2010). Life Cycle Assessment for biodiesel production under Greek climate conditions. Journal of Cleaner Production, 18(4), 328-335. http://dx.doi.org/10.1016/j.jclepro.200 9.11 .002

Van Gerpen, J., Shanks, B., Pruszko, R., Clements, D., \& Knothe, G. (2004). Biodiesel Production Technology. Subcontractor report NREL/SR-510-36244, subcontract No. ACO-2-35016-01.

Young, S. (2011). Inedible vegetable oils and their derivatives for alternative diesel fuels in CI engines: A review. Renewable and sustainable Energy Reviews, 15(1), 131-149. http://dx.doi.org/10.1016/j.rser.2010.08.012 


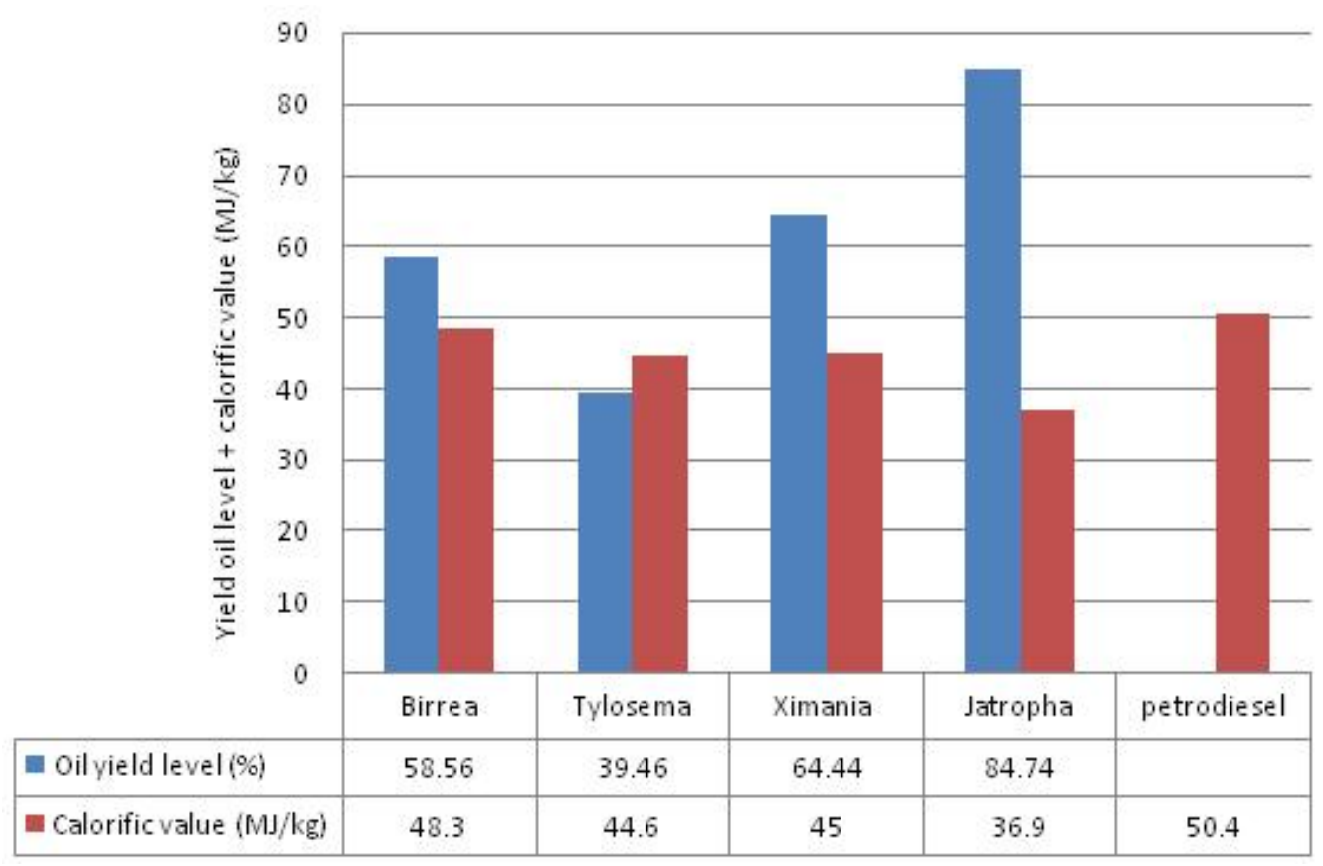

Figure 1. Plant oil yield levels and calorific values for selected species and petrodiesel fuel

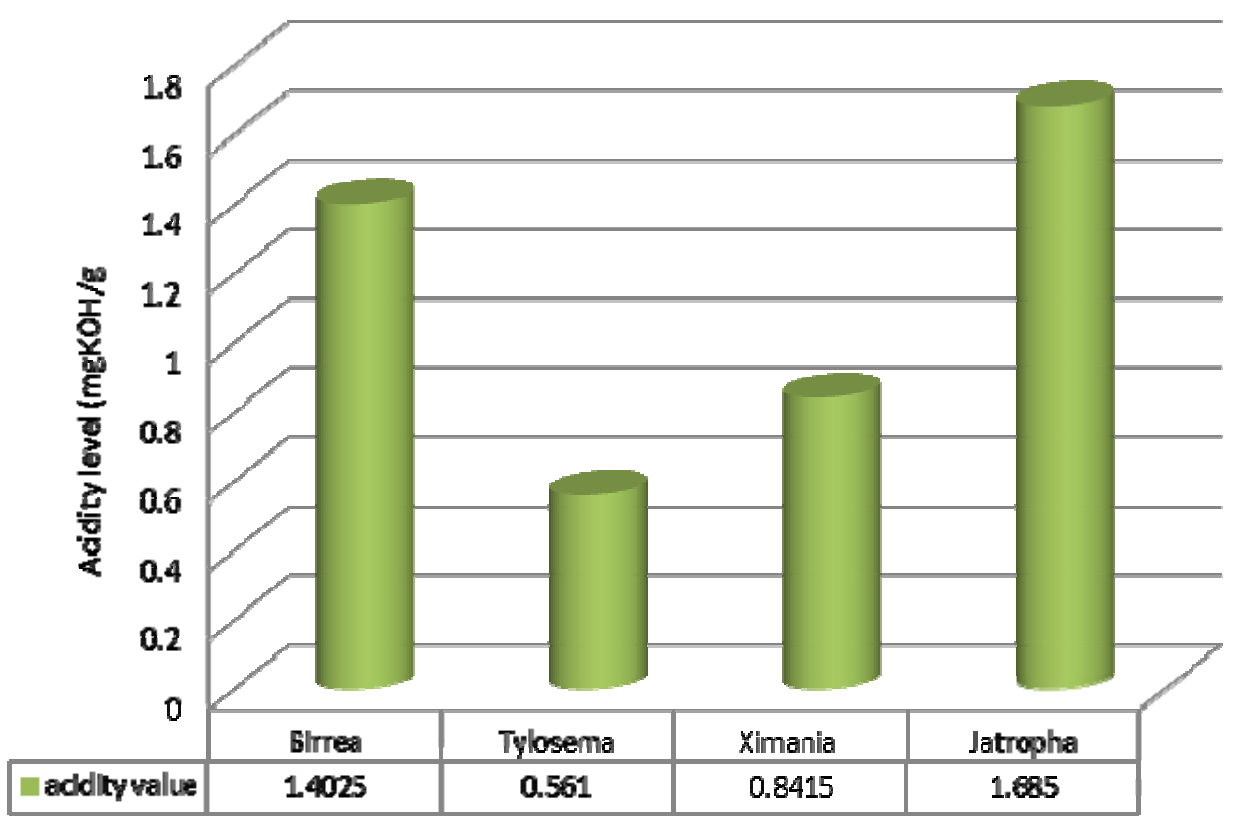

Figure 2. Acidity levels for selected indigenous plant oils and jatropha oil 